\title{
Tangence
}

\section{L'identitaire allophone : les modèles allemand et québécois}

\section{Hans-Jürgen Greif}

Numéro 59, janvier 1999

Écrivains d'ailleurs

URI : https://id.erudit.org/iderudit/025994ar

DOI : https://doi.org/10.7202/025994ar

Aller au sommaire du numéro

Éditeur(s)

Tangence

ISSN

0226-9554 (imprimé)

1710-0305 (numérique)

Découvrir la revue

Citer cet article

Greif, H.-J. (1999). L'identitaire allophone : les modèles allemand et québécois.

Tangence, (59), 87-111. https://doi.org/10.7202/025994ar d'utilisation que vous pouvez consulter en ligne.

https://apropos.erudit.org/fr/usagers/politique-dutilisation/ 


\section{L'identitaire allophone : les modèles allemand et québécois Hans-Jürgen Greif}

Lors d'un récent colloque sur la littérature allophone en République fédérale d'Allemagne ${ }^{1}$, les interventions des participants faisaient ressortir les difficultés de situer cette littérature en émergence par rapport à la littérature dite "nationale". La question qui sous-tendait la discussion était celle-ci: "Où se situe l'écrivain qui s'exprime dans une langue qui n'est pas la sienne, dans un pays d'adoption, et que devient-il?" Les analyses des stratégies d'intégration de cette nouvelle littérature, les tentatives de son appropriation ou de son rejet dans un pays qui n'est pas, officiellement, une terre d'immigration, ont vite fait d'amener des points de comparaison avec des procédés similaires dans d'autres pays occidentaux. Comparer la situation de la littérature allophone au Québec, déclaré terre d'immigration, et celle de l'Allemagne signifie relever non seulement des points de convergence dans les politiques gouvernementales, mais aussi les interventions des institutions culturelles, révélatrices à bien des égards. Il ne s'agit pas, ici, de favoriser tel ou tel modèle d'appropriation, d'intégration ou de transfert mais de relever les différentes approches d'une politique culturelle sur des bases similaires et différentes à la fois.

\section{L'Allemagne: un bref état de la question}

Dans son Histoire du calife cigogne, Wilhelm Hauff ${ }^{2}$ nous raconte comment Chasid, calife de Bagdad, et son vizir Mansor acquièrent d'un vendeur itinérant un morceau de papier sur lequel est inscrit un mot magique qui a le pouvoir de changer l'apparence de celui qui le prononce trois fois, en s'inclinant autant de fois vers l'Est. Mais attention: interdiction formelle de rire aussi longtemps que dure la métamorphose, autrement, la punition sera terrible, puisqu'ils ne pourront plus réintégrer leur ancienne

\footnotetext{
1 Organisé par le Centre culturel allemand à Tunis, du 2 au 4 novembre 1996.

2 Wilhelm Hauff, Maerchen-Almanach auf das Jabr 1826, für Söbne und Töchter gebildeter Stände, J.B. Metzlersche Buchhandlung, 1826.
} 
identité. L'intérêt du conte réside, bien entendu, dans cette punition; elle s'avérera pourtant bénéfique pour les deux personnages: en prononçant le mot latin magique - "mutabor", qui veut dire "je serai changé" - calife et vizir, très intrigués par la conversation de deux cigognes, veulent en savoir davantage. Ils se transforment donc en cigognes; du coup, ils comprennent la langue de leur nouvel entourage et participent à la vie de cigogne. Mais voilà : ce nouveau contexte leur paraît si drôle qu'ils en rient. Ils viennent de transgresser la loi, sont prisonniers de leur nouvelle identité, ils ont oublié le mot magique. Les deux malheureux compères ne peuvent plus s'adresser à leurs sujets humains dans leur ancienne langue pour leur dire qui ils sont, bien qu'ils soient encore capables de converser entre eux. Naturellement, l'affaire entière s'avère un infâme complot, ourdi par un sorcier, ennemi juré du calife. La panique s'empare des deux hommes-cigognes, mais tout rentre dans l'ordre: ils réintègrent leur ancienne identité par la ruse d'une femme; le sorcier sera pendu; la femme salvatrice devient l'épouse du calife. Il ne s'agissait que d'une aventure qui fera bien rire encore les enfants du couple heureux.

D'un côté, le conte de Hauff s'inscrit clairement dans la tradition orientalisante de la littérature européenne du $\mathrm{XIX}^{e}$ siècle. De l'autre, à cause de l'invasion napoléonienne, et de la montée du nationalisme en Allemagne, le texte porte un message très clair: changer d'identité est dangereux; rien ne vaut l'arrimage solide à la culture traditionnelle; passer d'une culture à l'autre, d'une langue à l'autre, comporte des risques graves aux suites irréversibles. Hauff tient en mémoire l'hégémonie étrangère, et plus particulièrement la française, culturelle d'abord (au xvIII siècle), politique ensuite, avec la défaite des États allemands par les armées de Napoléon $I^{\text {er }}$. Devant cette menace, l'écrivain met ses compatriotes en garde: un seul moment d'inattention, un désir pervers, et le mal est fait. Ne comptons pas sur la ruse pour réintégrer l'ancien moi, elle appartient au monde du merveilleux. En même temps, le texte révèle des sentiments facilement cernables: la peur d'être autre, la crainte de perdre à jamais l'ancien pays et son contexte culturel, ainsi que l'angoisse devant l'inattendu.

Le conte de Hauff traduit fidèlement l'angoisse d'un peuple ${ }^{3}$ qui avait, depuis le début $\mathrm{du} \mathrm{XvII}^{\mathrm{e}}$ siècle, connu une longue suite

3 L'appellation "peuple allemand. n'est, en fait, justifiable qu'à partir du dernier tiers du XIX ${ }^{e}$ siècle, après la guerre franco-prussienne (1870-1871), 
d'invasions par des forces étrangères ${ }^{4}$. La présence de l'Autre sur le sol allemand est perçue, depuis longtemps, comme une menace ou un irritant dont il faut se débarrasser, de crainte qu'il puisse infiltrer et "dénaturer le génie allemand" 5 . Cela explique, en partie du moins, l'explosion de ressentiments et de haine contre la minorité juive cohabitant depuis des siècles avec les Allemands de souche sous le troisième Reich ${ }^{6}$. Après la défaite de 1945 et avec le brutal réveil de la conscience allemande (de la partie occidentale, surtout) face à l'Holocauste, la reconstruction d'un pays sous domination étrangère et le boom économique des années cinquante et soixante ont provoqué l'arrivée massive de travailleurs étrangers sur le sol (ouest)allemand, plus particulièrement des ressortissants turcs, yougoslaves et italiens, et dont les descendants se trouvent dans la situation paradoxale d'être nés en Allemagne sans toutefois détenir un passeport allemand ${ }^{7}$. Afin

puisque le territoire où prédominait la langue allemande était jusqu'alors fractionné en de nombreux États autonomes, les rendant vulnérables aux attaques des grandes puissances, situation dont profita Napoléon $\mathrm{I}^{\mathrm{er}}$. Voir aussi note 5 .

4 Comme la Guerre de Trente Ans (1618-1648), qui a laissé un traumatisme profond dans la mémoire allemande, se reflétant encore aujourd'hui dans certaines locutions. Ce sentiment est comparable à celui d'autres nations européennes dont l'histoire est marquée par des invasions et des conflits prolongés, résultant en une méfiance profonde envers l'Autre, l'Étranger (France-Angleterre, Guerre de Cent Ans; Portugal et Espagne, invasion par les Maures; Italie et les dominations maure, germanique, espagnole, française, autrichienne; les nombreuses invasions germanique et russe en Polor gne, etc.)

5 Voir à ce sujet l'entretien avec Liah Greenfeld, dans Marcos Ancelovici et Francis Dupuis-Déri (dir.), L'archipel identitaire, Montréal, Boréal, 1997, au sujet du choix entre nationalisme civique ou ethnique, ainsi que son étude Nationalism. Five Roads to Modemity, Cambridge, Harvard University Press, 1992. Greenfeld soutient la thèse que le monde moderne est le résultat du nationalisme, résultat d'une crise identitaire, issue du contact avec d'autres formes (externes) du pouvoir; elle cite comme exemples la Grande-Bretagne et l'émergence de la conscience nationale française vers 1750; elle cite, avec raison, la prise de conscience nationale en Allemagne à l'ère du romantisme.

6 Pour la tradition juive en Allemagne, voir l'étude de Hans Küng, Le judaïsme, Paris, Seuil, 1995, plus particulièrement p. 265-372.

7 Pour la situation des immigrants, voir Anne-Marie Le Gloannec (dir.), L'état de l'Allemagne, Paris, Éd. La Découverte, 1995, plus particulièrement p. 141142 et 215-219. La situation des descendants de ces émigrés de la première heure est d'autant plus consternante qu'ils sont nés en territoire allemand, tandis que les nombreux rapatriés ("Aussiedler" de régions des pays de l'Est déclarées "zones d'expulsion"), nés à l'étranger, obtiennent sans difficulté un 
90

de clarifier le statut des étrangers en sol allemand, le gouvernement a présenté, le 9 juillet 1990, la Loi concernant les ressortissants étrangers ("Ausländergesetz") ${ }^{8}$, modifiée le 26 juin 1992. Cette loi exclut, dans une large mesure, les ressortissants étrangers de la vie politique et communale: ainsi, un ressortissant étranger de moins de 23 ans ne peut obtenir son passeport allemand que s'il a vécu sur le sol allemand depuis huit ans et s'il a fréquenté une école allemande pendant six ans tout en renonçant à sa nationalité d'origine (alinéa 85); un étranger adulte doit avoir vécu quinze ans en sol allemand avant d'obtenir son passeport, pourvu qu'il abandonne la nationalité de son pays d'origine (alinéa 86). On comprend pourquoi d'importants groupes de pression revendiquent une meilleure intégration des étrangers à la vie politique et communale en Allemagne ${ }^{9}$. Ce débat a du moins clarifié les notions de "nationalité", reliée à l'ethnicité, et de "citoyenneté", qui signifie un lien politique avec l'Allemagne ${ }^{10}$.

passeport allemand au nom du "droit du sang" (jus sanguinis); toutefois, ce droit n'est plus appliqué, de façon automatique, depuis 1993. S'ajoutent les demandeurs d'asile politique; cependant, le flot des derniers a considérablement diminué après l'amendement, le 26 mai 1992, de l'article 16 de la Loi fondamentale qui restreint désormais le droit d'entrée aux réfugiés.

8 Le titre exact se lit comme suit: "Loi sur l'entrée et le séjour d'étrangers sur le sol de la République fédérale d'Allemage" (Gesetz über die Einreise und den Aufenthalt von Ausländern im Bundesgebiet); cette loi comprend 106 articles, régissant les différents visas de séjour, l'obtention d'un passeport, le refoulement des ressortissants étrangers, les mesures légales s'y rattachant et les "dispositions facilitant l'obtention de la nationalité allemande. Le tentatives de l'opposition à la diète (Bundestag) visant une réforme de la loi sur la nationalité allemande n'ont pas eu de succès.

9 Voir L'état de l'Allemagne, op. cit., p. 215 suiv. À la fin de 1992, près de 6,5 millions personnes d'origine étrangère vivaient en Allemagne, comptant pour $5,7 \%$ de la population. Les deux groupes ethniques les plus importants restent les ressortissants turcs (près de 1,8 million) et ex-yougoslaves $(900000)$, suivis des Italiens $(500000)$.

10 Ibid., p. 215. La critique allemande n'a pas encore systématisé ses travaux sur le corpus allophone. Une pionnière dans le domaine est toutefois Irmgard Ackermann, qui a travaillé inlassablement à la reconnaissance de cette littérature en émergence, et dont les plus belles réalisations sont l'anthologie $A l s$ Fremder in Deutschland (Être étranger en Allemagne), dtv, München, 1982, $\mathrm{n}^{\circ} 1770$, son introduction à : Karl Esselborn (dir.), Über die Grenzen (Au-delà des frontières), dtv, München, 1987, $\mathrm{n}^{\circ}$ 10803; elle a publié de nombreux articles dans des revues spécialisées. Sa récente publication d'une anthologie pour le compte de l'Agence gouvernementale Inter Nationes, Fremde AugenBlicke. Mebrkulturelle Literatur in Deutschland (Regards d'étrangers. Littérature pluriculturelle en Allemagne), Bonn, Inter Nationes, 1996 regroupe seize 
Il n'est donc pas surprenant que les intellectuels d'origine étrangère, issus essentiellement des deuxième et troisième générations de travailleurs immigrés ("Gastarbeiter", ce qui se traduit littéralement par "travailleur invité", signifiant ainsi un séjour du ressortissant étranger limité dans le temps), et plus particulièrement les écrivains, prennent position vis-à-vis de leur statut politique et social en Allemagne. Leur questionnement quant à leur relation et avec le pays hôte et avec la patrie de leurs parents ou grand-parents ainsi que d'un possible modèle de coexistence avec l'autre résultent des revendications concernant leur place dans le cadre de la littérature nationale.

\section{Le défi d'une littérature en émergence}

Dans une entrevue avec le critique littéraire Fritz J. Raddatz, le poète d'origine andalouse José F.A. Oliver disait: "Mes poèmes ne sont autre chose que le défi permanent qui consiste à comprendre cette langue [l'allemand]" 11 . Pourtant, Oliver est né en Allemagne (1961); il y a fréquenté l'école, terminé ses études universitaires, co-fondé l'organisation au titre significatif "PoLiKunst " ("Polynationaler Literatur- und Kunstverein", Association artistique et littéraire polynationale, 1984). Depuis, il publie régulièrement ses poèmes sous forme de recueil ou dans des revues allemandes. Il est clairement porteur de deux cultures; son allemand est légèrement teinté par l'accent du Wurttemberg (comme son espagnol l'est par l'accent andalou). S'il dit qu'il tente de comprendre l'allemand par ses poèmes, il ne se réfère pas, bien entendu, au sens strict des mots, mais à l'opposition des contextes culturels espagnol et allemand, difficilement conciliables selon lui. C'est ainsi qu'il tente de pratiquer le métissage des deux cultures, transposant de son contexte andalou - qu'il renouvelle sans cesse - des images nouvelles et inhabituelles pour le lecteur allemand. En d'autres termes: le poète rend transparents

des écrivains allophones les plus représentatifs. - Pour des réflexions théoriques concernant les concepts "Multiculturalisme ", "Fondamentalisme ", "Coexistence", "Identité", voir Merkur, nos 522 et $523,\left(9 / 10,46^{\mathrm{e}}\right.$ année, septembre/octobre 1992), particulièrement les contributions de Bernard Lewis, Manfred Henningsen et Berndt Ostendorf, qui se réfèrent cependant souvent au modèle américain.

11 Die Zeit, $\mathrm{n}^{\circ} 26$ (24 juin 1994), à propos de la publication du recueil de poésie Gastling (L'invité) de Oliver (1993). 
dans sa langue d'adoption des emprunts à la langue maternelle (qui est l'espagnol; Oliver a fréquenté simultanément des classes d'espagnol et d'allemand jusqu'à son entrée au lycée); ses références sont souvent empruntées au monde hispanophone, qu'il tente de recréer dans une "musique" nouvelle, aux accents inconnus des Allemands.

\section{De la langue d'emprunt à la cohabitation}

Oliver est né en Forêt Noire; d'autres poètes, écrivains et artistes (arts plastiques, danse, thêâtre) sont encore nés dans le pays de leurs parents, mais arrivés dès l'enfance en Allemagne. Pour tous, l'accès à "l'autre patrie" s'opère par la présence des parents parlant la langue d'origine; autrement dit, la question de la langue est intimement liée au problème de l'identitaire. Ainsi, Franco Biondi, qui a appris l'allemand à l'âge de dix-huit ans ${ }^{12}$, ressent toujours profondément sa qualité d'étranger, mais refuse de quitter le pays d'adoption pour lequel il éprouve un profond attachement. Selon lui, l'allemand parlé par un immigrant italien n'est pas une langue artificielle, exprimant un monde ni italien ni allemand: "Dans la mesure où les étrangers qui vivent ici enrichissent la langue allemande de notions spécifiques, nous arrivons à une synthèse: nous transposons dans la langue ce qui se passe dans la vie quotidienne. C'est pourquoi la frontière entre langue artificielle et langue de tous les jours n'est plus nettement identifiable." 13

12 Franco Biondi (*1947 à Forlì, en Italie). Ses textes les plus connus restent Passavantis Rückkebr (Le retour de Passavanti, 1976, qui traite de l'impossible retour en Italie), publié chez Verlag Atelier im Bauemhaus, Fischerhude 1982, et Abschied der zerschellten Jabre (L'adieu des années brisées), Kiel, Neuer Malik Verlag, 1984. Avec Fruttuoso Piccolo (*1953 à Stanghella; Arlecchino Gastarbeiter (Harlequin, travailleur immigré], Postscriptum Verlag, Hannover, 1985), Biondi est l'un des écrivains d'origine italienne les plus en vue. Pour des données bio-bibliographiques d'auteurs dont la langue maternelle est l'italien, voir l'étude de Gino Chiellino, Literatur und Identität in der Fremde (Littérature et identité à l'étranger, Neuer Malik Verlag, Kiel, 1989), pp. 151-155.

13 Cité par Carmine (Gino) Chiellino, Die Reise bält an. Ausländische Künstler in der Bundesrepublik (Le voyage se poursuit. Artistes étrangers en RFA), München, C.H. Beck, 1988, p. 27. Une excellente étude de Chiellino, Literatur und Identität in der Fremde, op. cit., traite de l'émergence d'auteurs d'origine italienne en RFA. Voir surtout la partie II, C: "Themen für eine Literatur in der Fremde" ("Thèmes pour une littérature à l'étranger"), p. 94-121. Les 
SAID, d'origine iranienne, un des poètes les plus importants et les plus célèbres parmi les allophones en Allemagne, perçoit le contact avec la culture allemande comme un défi permanent: "Le danger d'être séduit par la richesse de la littérature allemande, d'être tenté de se mesurer à certaines formes littéraires et de les concurrencer est grand. Nous [les écrivains d'origine étrangère] pouvons et devons rester originaux, parler de notre monde, dans cette [nouvelle] langue que nous devons affiner au maximum, sans jamais en sacrifier le contenu. Je crois que la langue allemande est toujours ouverte à quelqu'un qui parle d'un monde étranger." ${ }^{14}$ Se dessine ici, comme chez Oliver, le projet non pas de l'intégration ou de l'assimilation, mais celui du métissage, du frottement entre les cultures, menant à l'enrichissement de la culture du pays d'accueil.

Cette attitude face à la langue du pays d'accueil présuppose une cohabitation fructueuse des deux cultures chez l'écrivain et leur acceptation. La situation change dès que la disparition de la culture d'origine est considérée comme la perte d'un bien précieux. C'est le cas d'Emine Sevgi Özdamar, d'origine turque ${ }^{15}$. Dans son recueil de récits Mutterzunge (Langue de mère), elle dit s'être rendu compte que le turc sonne faux en milieu berlinois, ou encore comme une langue apprise. Dès lors, elle veut se réapproprier le monde de son origine, celui d'avant 1927 et Atatürk, par l'entremise de l'écriture et de la langue arabes afin de pouvoir lire le Coran. L'arabe se profile comme la langue des pères, et la langue de l'amour; il établit des ponts avec le passé. Dans le premier texte du recueil, elle dit, au tout début: "Si seulement je savais quand j'ai perdu ma langue de mère" (p. 7). Elle retrace les stations de sa vie, et souligne l'impossibilité de retourner en

ressortissants italiens, très critiques du mode de vie, de la nourriture, du climat en RFA, conçoivent souvent leur séjour en Allemagne comme un mal passager et espèrent pouvoir retourner vivre en Italie.

14 Cité par Carmine Chiellino, op. cit., p. 84. SAID (pseudonyme; "1947 à Téhéran, vit en RFA depuis 1965) est devenu célèbre dès son premier recueil de poèmes, Liebesgedichte (Poèmes d'amour, 1981). Les recueils Dann schreie ich bis Stille ist (Alors je crie jusqu'à ce que silence se fasse, 1990) et Selbstbildnis für eine ferme Mutter (Autoportrait pour une mère lointaine, 1992) lui ont valu des critiques exceptionnellement élogieuses. En 1991, SAID a reçu le Prix Adelbert-von-Chamisso de l'Académie des Beaux-Arts de Bavière.

15 Emine Sevgi Özdamar ("1946 à Malatya, Turquie), Mutterzunge (Langue de mère), récits, Rotbuch Verlag, Berlin 1993. Özdamar vit en RFA depuis 1965. En 1991, elle a reçu le prestigieux prix Ingeborg-Bachmann. 
94

Turquie puisqu'elle y est considérée comme élément subversif. Elle se tourne vers le monde du passé, désormais imaginaire, en compagnie d'un vieux sage turc. Pour Özdamar, il s'agit de reconquérir l'identité première, celle qui est enfouie au plus profond d'elle-même, et de la libérer de ce qui a pu la contaminer (un système politique construit sur le modèle occidental, et inadapté à la culture turque, le mode de vie à Berlin).

Mais ce genre de texte qu'à la limite nous pourrions qualifier de "migrant", par opposition à "métisse" ${ }^{16}$, n'est représentatif que pour un seul courant dans la littérature allophone en Allemagne qui place au centre de sa problématique la question de l'identitaire. D'autres auteurs allophones, surtout ceux de la deuxième, et certainement la troisième génération, ont fait le deuil de l'ancienne patrie qu'ils considèrent désormais comme faisant partie intégrante de leur héritage culturel, fractionné. Ils se tournent résolument vers une société aux multiples facettes ethniques ${ }^{17}$. Si Özdamar retourne à la culture de ses ancêtres, elle le fait dans le souci de retrouver un cadre lui permettant de s'identifier à une échelle de valeurs immuable, hors du temps et de l'espace, sans lien direct avec l'Allemagne ou avec la Turquie contemporaines. Puisque ni la famille, ni le(s) système(s) politique(s) ne lui offrent de points de référence spirituels, et encore moins le monde professionnel (Özdamar travaille comme actrice et dramaturge en Allemagne), elle se réapproprie la langue perdue et le texte au centre de sa culture d'origine, se soutirant ainsi à toute tentative

16 Nous nous basons sur la définition de ces termes par Robert Berrouët-Oriol et Robert Fournier, élaborée dans "L'émergence des écritures migrantes et métisses au Québec", Québec Studies, no 14, printemps/été 1992, p. 12: "Les écritures migrantes forment un micro-corpus d'œuvres littéraires produites par des sujets migrants: ces écritures sont celles du corps et de la mémoire; elles sont, pour l'essentiel, travaillées par un référent massif, le pays laissé ou perdu [...]. Les écritures métisses forment également un micro-corpus d'ouvres littéraires produites par [...] des sujets migrants se réappropriant l'Ici, inscrivant la fiction - encore habitée par la mémoire originelle — dans le spatio-temporel de l'Ici; ce sont des écritures de la perte, jamais achevées, de l'errance et du deuil." (Les auteurs soulignent.) À ce sujet, voir également Pierre Nepveu, L'écologie du réel: mont et naissance de la littérature québécoise contemporaine, Boréal, Montréal 1988.

17 D'excellents exemples de littérature migrante de la première génération sont les poètes Aysel Özakin, d'origine turque, dont les textes évoquent souvent la vie de ses parents et grands-parents turcs, et Adel Karasholi, né en Syrie, qui reste profondément attaché à son ancienne patrie, comme son compatriote Suleman Taufiq. 
intégratrice ou assimilatrice. Depuis que la ferveur religieuse a grandi, surtout en milieu musulman, et par suite de l'hostilité marquée de la droite allemande vis-à-vis des communautés ethniques, on assiste à un repli de ces mêmes communautés sur elles-mêmes, provoquant ainsi une nouvelle ghettoïsation que l'on pourrait qualifier d'"intérieure". C'est justement ce phénomène, aggravé par la politique de Bonn en matière d'immigration, que ces mêmes auteurs avaient voulu éviter, à la fin des années quatre-vingt (avant la chute du mur), reconnaissant clairement les dangers d'un multiculturalisme qui, sous prétexte de vouloir sauvegarder le caractère spécifique de chaque groupe ethnique, révèle ses effets plutôt pervers: au lieu de favoriser l'interaction entre groupes ethniques et population de souche, il encourage les ressortissants étrangers à se regrouper dans des ghettos (culturels ou urbains) qui constituent autant de barrières à l'intérieur du pays d'accueil, empêchant les échanges avec la culture allemande. Ainsi, cette forme de multiculturalisme maintient une foule de "romans mémoriels" en terre d'accueil, en transférant souvent les problèmes interethniques du pays d'origine au pays hôte ${ }^{18}$.

\section{Une nouvelle voie... en péril}

À la fin de la dernière décennie, et au début des années quatre-vingt-dix, l'Allemagne, du moins celle comprenant le territoire des anciens Länder, semblait sur une voie d'interaction culturelle entre groupes ethiques et population de souche allemande: la présence de millions d'étrangers, surtout en milieu urbain, avait amené un profond changement des mentalités, un frottement continuel entre les cultures et un rapprochement prometteur ${ }^{19}$. Depuis les émeutes xénophobes qui ont débuté en 1991, bien des acquis semblent être remis en cause et un durcissement des positions Allemands-étrangers se fait nettement sentir, sans que le gouvernement prenne des mesures pour récupérer le précieux

18 Le terme "roman mémoriel "est employé ici dans le sens où l'utilise Régine Robin dans Le roman mémoriel. De l'bistoire à l'écriture du bors-lieu, Montréal, Le Préambule, coll. "L'univers du discours", 1989

19 Lors des émeutes dirigées par la droite contre les ressortissants étrangers, entre 1991 et 1995, les médias ont montré surtout les actes violents commis par la droite, mais ont presque passé sous silence les démonstrations d'appui à la présence d'étrangers en sol allemand (beaucoup moins spectaculaires, il est vrai) auxquelles participaient des millions d'Allemands. 
96

terrain perdu, comme le démontrent les publications au ton plutôt revendicateur, surtout d'intellectuels d'origine turque ${ }^{20}$.

Pourtant, bon nombre d'écrivains poursuivent la voie du dialogue. Il faut souligner cependant que le bassin des narrataires s'est considérablement agrandi depuis la chute du Mur, et que les mentalités dans les nouveaux Länder sont moins préparées à la présence d'autres ethnies en sol allemand, comme l'ont bien prouvé les émeutes raciales. Bien entendu, ces narrataires tiennent lieu d'ersatz: puisque l'écrivain ne peut plus se faire entendre dans sa langue d'origine, il emprunte l'allemand, transgressant ainsi les frontières — imaginaires ou réelles — entre son propre groupe ethnique et les Allemands de souche. Par l'utilisation de l'allemand comme moyen de communication (et dans une tentative d'identification), il apporte, d'une part, à l'allemand une foule d'images de son propre contexte culturel, comme nous l'avons souligné chez Oliver et Biondi. D'autre part, et c'est ce qui nous semble plus important encore, il établit par là un tapport de bordure avec la langue maternelle. En utilisant l'allemand, l'écrivain allophone participe de la culture allemande tout en exprimant sa propre étrangeté, relevant du coup pour les narrataires (allophones comme lui, et/ou lecteurs d'origine allemande) la problématique entourant l'existence même des ressortissants étrangers.

\section{Des textes dérangeants}

Pour certains auteurs, la question identitaire semble avoir été soit résolue, soit (temporairement?) mise de côté ${ }^{21}$. Dans son

20 Voir l'étude de Faruk Sen, "1961 bis 1993: Eine kurze Geschichte der Türken in Deutschland" (1961-1993: une brève histoire des turcs en Allemagne)*, dans Deutscbe Türken. Das Ende der Geduld/Türk Almanlar. Sabmn sonu (Turcs allemands. La fin de la patience, édition bilingue), Claus Langewie/Zafer Senocak dir.), Rowohlt, Reinbek bei Hamburg, coll. aktuell, $\mathrm{n}^{\circ} 13426$, p. 17-36, ainsi que le recueil d'essais de Zafer Senocak (*1961 à Ankara, Turquie, depuis 1970 en RFA): Atlas des tropischen Deutschland (Atlas de l'Allemagne des tropiques), Berlin, Babel Verlag, 1993, particulièrement p. 56-61 "Kultur und Nation - Deutsche Hypotheken" ("Culture et nation - hypothèqyes allemandes"). Voir également Lucas Delattre, "L'islam en Allemagne, plus toléré qu'intégré ", Le Monde, 18 février 1997.

21 Ici, il faut mentionner un cas assez particulier et qui montre que l'allophonie peut être utilisée comme levier publicitaire: l'auteur "turc" Jacob Arjouni s'est fait connaître avec une série de romans policiers, tous acclamés par la critique, comme Happy birthday, Türke! (Bon anniversaire, Turcl, 1987), Mebr 
premier roman, Renan Demirkan avait encore pris ses références dans son monde d'origine. Mais son deuxième, Die Frau mit Bart $^{22}$, confronte deux Allemandes de souche qui se retrouvent sur une île en mer du Nord, avec leurs problèmes particuliers: travail et carrière, relations amoureuses, difficulté d'être mère. Une fois seulement, Demirkan aborde le sujet d'une culture en voie de disparition, sans cependant s'appuyer sur sa propre culture d'origine: elle évoque la mort du dialecte et des coutumes ancestrales frisonnes, en citant un vieux Frison, attristé de constater que les enfants ne parlent plus la langue de leurs parents, que les jeunes gens quittent les îles, et que le "progrès" a réussi là où même les nazis avaient échoué en essayant d'interdire l'utilisation du frison. Les analogies entre Frisons et Turcs (ou tout autre groupe ethnique) deviennent plus claires lors de la description du mode de vie des Frisons qui ont quitté leur patrie: ils sont partis en Amérique, terre promise, y ont vécu pauvrement pour retourner plus tard sur les îles en faux richards (p. 56 suiv.). Mais la référence au propre contexte culturel reste l'exception; Demirkan semble vouloir prendre sa place comme auteure de la littérature nationale. Les liens avec la Turquie sont devenus imperceptibles, ou accessibles seulement par le biais de la culture du pays d'accueil, comme chez Yüksel Pazarkaya dans son recueil de

Bier (Davantage de bière) et Ein Mann, ein Mord (Un bomme, un meurtre, 1991), Magic Hoffmann (1996; tous chez Diogenes, Zurich). "Jakob Arjouni", de son vrai nom Jakob Bothe, fils du dramaturge allemand Hans Günter Michelsen et de Ursula Bothe, directrice d'une maison d'édition allemande, exploite intelligemment l'intérêt que suscite la littérature allophone en Allemagne. (cf. Hajo Steinert: "Ein Berliner Taugenichts" (Un bon à rien berlinais"), Focus, Munich, 11. 3. 1996; Daniel Brunner: "Geschichten erfinden hat mir schon immer Spaß gemacht" (Inventer des histoires m'a toujours fait plaisir"), Annabelle, Zurich, 19. 04. 1996. L'auteur de cet article tient à remercier Christoph Vatter de l'université de la Sarre pour ces renseignements.) Il est intéressant à noter que les romans en question présentent, de manière tout à fait convaincante, les difficultés de coexistence entre Turcs et Allemands, le discours raciste que tiennent les deux communautés l'une sur l'autre, les tentatives d'entrer dans la culture de l'Autre. En réinventant le roman policier américain, transposé en milieu allemand, avec un protagoniste d'origine turque qui s'exprime en un allemand parfait, Arjouni-Bothe indique le frottement des cultures, rendant son détective vulnérable et imperméable à la fois aux attaques racistes.

22 Die Frau mit Bart (La femme à la barbe, 1994) est le deuxième roman (après Scbwarzer Tee mit zwei Stück Zucker [Thé noir avec deux morceaux de sucrel, 1991) de l'auteure d'origine turque (*1955), qui vit depuis 1962 en RFA. Elle s'est surtout fait connaître comme actrice (film et thêâtre). 
98

poésies Die Liebe von der Liebe, (L'amour de l'amour) où le haiku japonais sert à exprimer la convergence des cultures ${ }^{23}$.

De manière générale on peut affirmer que le pays d'origine est nettement présent dans les ceuvres d'auteurs allophones, surtout s'ils viennent du bassin méditerranéen ${ }^{24}$. L'intégration de textes allophones dans le cadre de la littérature nationale avec une thématique non spécifique et sans référence à la culture d'origine reste encore l'exception puisque, de l'avis de la plupart des écrivains allophones, les Allemands n'ont pas encore compris que leur pays ne reflète plus une seule culture. Dans son essai "Devenir Allemands - rester Turcs", paru quelques années après la réunification, Zafer Senocak exprime clairement sa frustration devant un Etat pris dans une glu monoculturelle:

Dans une Allemagne unifiée, la diversité [culturelle] est en danger de disparaître. Non seulement les Allemands de l'Est s'opposent-ils à cette tendance, la tierce Allemagne avec ses 6,5 millions d'étrangers politiquement dépossédés de leurs droits n'acceptera plus longtemps cette tendance vers le monoculturalisme.

L'Allemagne se trouve à la croisée des chemins: ou bien elle accomplit la voie vers l'État moderne qui ne se définit plus exclusivement en termes ethno-sociaux, ou bien elle retombe dans les formes archaïques d'une collectivité où l'appartenance est réglée par l'origine ethnique, où le collectif prime sur l'individu, où l'immigration est impossible et le racisme une loi tacite [...]. Les suites psychologiques sont d'ores et déjà identifiables: la scission de la société selon des critères ethniques, la perte de confiance dans les institutions de l'État, le retrait des minorités dans des fictions d'identités personnelles, la formation de ghettos, l'accroissement d'idéologies fondamentalistes et intolérantes, basées sur la violence. ${ }^{25}$

Senocak poursuit en soutenant que l'immigrant ne doit plus être considéré comme un Allemand en devenir à qui manqueraient

23 Dans Ich möcbte Freuden schreiben (Je veux écrire des joies), Verlag Atelier im Bauernhaus, Fischerhude 1983. Pour une réflexion sur la littérature nationale, voir Michel Espagne et Michael Werner (dir), Pbilologiques III: Qu'est-ce qu'une littérature nationale? Approches pour une théorie interculturelle du champ littéraire, Paris, Éditions de la maison des sciences de lhomme, 1990.

24 Il suffit d'isoler la thématique des textes réunis dans les cleux anthologies citées dans la note 10.

25 Deutsche Türken. Das Ende der Geduld, op. cit., p. 11. 
la langue et le contexte culturel, mais comme étranger, ce qui signifie que les Allemands doivent élargir, de leur côté, la notion d'"être Allemand". En postulant non plus le multiculturalisme empêchant l'échange fructueux entre cultures, mais un profond changement de mentalités menant à des situations de bordure où les cultures s'interpénètrent, créant ainsi une nouvelle identité, il s'inscrit dans la lignée des auteurs tournés vers l'avenir. Senocak ne relève pas, ici, un argument important dont avait déjà usé Franco Biondi dans une entrevue, attaquant de front l'identité nationale des Allemands. Partant de la question: "Comment voyez-vous lla rencontre des cultures?", Biondi explique: "C'est une rencontre de plusieurs [cultures]. Je n'ai jamais pensé qu'il devrait s'agir exclusivement d'une rencontre entre Allemands et Italiens, mais une rencontre des différentes minorités et des différents groupes d'Allemands, car les Allemands ne forment pas non plus un groupe homogène. "26 Un des plus beaux exemples du concept d'une existence composite dont rêve l'avant-garde des écrivains allophones nous est donné par Zehra Çrak, dans son recueil de poésies et de textes courts Vogel auf dem Rücken eines Elefanten:

Je ne préfère ni ma culture turque ni ma culture allemande. Je vis et tends vers une culture mixte. C'est par la force des choses que je vis comme je le fais, puisque je ne vis ni dans un iglou, en Alaska ni dans une hutte, en Anatolie. [...] J'adorerais me réveiller à la japonaise dans un lit à même le plancher avec des portes transparentes coulissantes. Puis, j'aimerais prendre un petit déjeuner anglais, pour travailler ensuite à la chinoise, de façon détachée, appliquée et avec beaucoup de zèle. Manger à la française et me baigner comme une Romaine, rassasiée comme un animal, serait merveilleux; je voudrais faire des randonnées pédestres en Bavière et danser comme une Africaine. J'aimerais dire mienne la patience russe et ne pas avoir à gagner ma vie à l'américaine. Ah, je voudrais avoir un passeport suisse sans que l'on me soupçonne être détentrice d'un compte en banque anonyme. J'aimerais m'endormir comme une Indienne sous forme d'oiseau sur le dos d'un éléphant et rêver du Bosphore à la manière turque.

Est-ce que je veux quelque chose où je puisse me reconnaitre ou quelque chose qui fasse que d'autres puissent me classer? ${ }^{27}$

26 Entrevue avec G. Chiellino, Die Reise bält an, op. cit., p. 33.

27 Zehra Girak (*1961 à Istanboul, arrivêe en 1963 en Allemagne); Vogel auf dem Rücken eines Elefanten (Oiseau sur le dos d'un éléphant), Kiepenheuer und Witsch, Berlin, 1991, p. 94. En 1994, Crrak a publié un autre recueil de 
100

Aucun autre écrivain allophone (et encore moins un écrivain de la littérature nationale) n'est allê aussi loin que Curak dans cette vision de l'individu en devenir, non plus fractionné mais intégrant une multitude d'autres cultures dans son existence, marquée par la postmodernité. D'un côté, elle rejette le monoculturalisme qui menace un État réfractaire à la reconnaissance de ressortissants étrangers et de leur(s) culture(s); de l'autre, elle montre la voie d'un métissage des cultures, créant ainsi les rapports de bordure nécessaires pour une meilleure interpénétration des groupes ethniques en sol allemand.

Il est curieux de constater qu'en Allemagne, la terminologie dans le débat concernant l'identitaire allophone ne comprenne pas (ou peu) le vocable "transculture"; auteurs et critiques préfèrent utiliser "multiculturalisme" (ou "pluriculturalisme"), "pluriethnicité ", ou d'autres termes encore, reflétant l'existence en parallèle plutôt que l'interaction culturelle. C'est ici que la comparaison avec le modèle du Québec prend toute son importance.

\section{Le Québec, terre d'immigration}

Dès les débuts de la colonisation, en 1608 (fondation de la ville de Québec), le Québec est une terre d'immigrés, français d'abord, anglais ensuite. Le peu d'intérêt soutenu dont fait preuve la France de Louis XIV et de ses successeurs s'avère désastreux pour l'équilibre démographique entre francophones et anglophones en Amérique du Nord. Les deux groupes ethniques ne s'unissent, on le sait bien, que pour repousser les Amêricains; le double héritage français (culturel) et britannique (institutions, législation) amène cependant une hésitation constante dans le comportement du groupe ethnique francophone, lui-même descendant d'immigrants ${ }^{28}$. Ce groupe, fortement métissé dès les débuts de la colonie accueille, surtout depuis 1960 , entre trente et cinquante mille

poésies chez le même éditeur, Fremde Flügel auf eigener Schulter (Ailes étrangères sur mon épaule). Nombreuses publications (récits, poésies) dans des anthologies. En 1993, l'auteure a reçu le Prix Friedrich-Hölderlin.

Cf. la thèse de Heinz Weinmann sur l'identitaire québécois, "Le Québec, entre la naissance de la nation, entre la nation et la méta-nation", Jean-Michel Lacroix et Fulvio Caccia (dir.), Métamorpboses d'une utopie, Presses de la Sorbonne Nouvelle, Éditions Triptyque, 1992, p. 119-130. L'auteur soutient que le Québécois hésite devant son identité parce qu'il ne sait pas qui est l'Autre qu'il s'agit d'éliminer pour constituer une nation. Voir surtout les p. 121 et 124-125. 
ressortissants étrangers annuellement qu'il tente d'intégrer dans l'ensemble de la population. C'est Montréal cependant que la majorité des immigrants choisissent pour s'établir ${ }^{29}$. D'après le recensement de 1991, des cinquante principaux pays de naissance tout près de 600000 ressortissants avaient choisi de s'installer au Québec, contre presque 4500000 pour le reste du Canada. Lorsque l'on compare les proportions démographiques entre francophones (environ le quart de la population totale du Canada) et anglophones de souche, il appert que presque deux fois moins d'étrangers choisissent le Québec comme terre d'accueil. La proportion ressortissants étrangers-population de souche francophone est pratiquement identique à celle de l'Allemagne, avec une différence fontamentale cependant: au Québec, la majorité des étrangers se concentrent en une seule ville, tandis qu'en Allemagne, ils sont répartis sur l'ensemble du territoire, avec des fortes concentrations de ressortissants turcs à Berlin et Francfort s. le Main. Les trois pays ayant fourni le plus de ressortissants au Québec sont l'Italie, la France et Haïti ${ }^{30}$.

Si l'on fait abstraction du contingent d'immigrants d'origine française - qui choisissent majoritairement le Québec à cause cle la langue officielle (30,6 pour cent s'établissent ailleurs qu'au Québec) - il est frappant de constater que les deux autres groupes ethniques en importance sont issus de pays qui, selon leurs écrivains établis au Québec, les ont "abandonnés" ou encore n'ont pas été en mesure de les "nourrir". En s'installant au Québec, l'immigrant suit le mythe nord-américain du nouveau

29 Les dernières statistiques indiquent que les efforts du gouvernement visant à répartir de façon plus uniforme l'immigration portent fruit: en 1996, 72,8 pour cent des immigrants ont choisi Montréal (1992: 85,5 pour cent). Cette baisse est également attribuable au taux de chômage élevé dans la métropole. (Source: Gouvernement du Québec, le Québec en mouvement. Statistiques sur l'immigration, édition 1997, ministère des Relations avec les citoyens et de l'Immigration.) Voir également L'immigration en région 1996. Statistiques sur l'immigration dans les régions administratives du Québec, 1997, publié par le même ministère

30 L'Allemagne vient en douzième place, 12705, contre 180525 pour le Canada (Population immigrée recensée au Québec en 1991: caractéristiques généra. les, coll. "Statistiques et indicateurs", $\mathrm{n}^{\circ} 3$, de l'ancien ministère des Communautés culturelles et de l'Immigration, 1991). Malheureusement, des données concernant la rétention d'immigrants n'étaient pas disponibles. Il est à présumer que les Allemands, plus familiers avec l'anglais qu'avec le français, s'installent davantage dans des provinces anglophones (Ontario, Alberta, Colombie britannique). 
102

départ et de la réussite matérielle: en Amérique, il peut briser l'ancienne hiérarchie soit sociale, soit familiale, ou les deux, de son pays d'origine tout en s'intégrant dans une société perçue comme plus "libre" et plus "Ouverte" et dans un pays "nouveau ". Contrairement à l'Allemagne, où les immigrants doivent s'insérer dans une société régie par des règles établies depuis de longues générations d'une population de vieille souche et à l'identité nationale assez clairement définie, les immigrants en terre d'Amérique prennent contact avec une population dont les membres sont eux-mêmes les descendants d'immigrants, porteurs du même rêve qu'eux. Théoriquement, les nouveaux arrivants peuvent donc compter sur la compréhension du groupe d'accueil.

Cependant, l'immigrant se rend vite compte que l'image projetée du pays d'accueil ne correspond pas ou peu à la réalité. En s'installant au Québec, il constate que la société d'accueil a développé sa propre problématique de l'identitaire. D'abord, il perçoit une société minoritaire sur le plan linguistique; s'il est installé à Montréal, officiellement deuxième ville en importance de langue française à l'extérieur de l'Hexagone, il entend et voit une multitude d'autres langues et de groupes ethniques dans une "ville schizophrène, patchwork linguistique, bouillie ethnique "31, où règne la loi du chacun pour soi, et où les habitants de vieille souche francophone le regardent souvent comme un intrus et un "voleur de job"32. L'immigrant en quête d'appui se tourne alors tout naturellement vers son propre groupe ethnique où il rencontre à nouveau, souvent sous forme réduite (et donc de façon plus exacerbée), l'échelle des valeurs, la hiérarchie sociale ou familiale du pays d'origine. En d'autres termes: il a bien changé de pays, mais il ne peut guère changer son habitus puisqu'il reste enfermé dans un cadre lui rappelant à tout moment son ancienne patrie.

La déception qui en résulte recoupe celle qu'expriment les immigrants turcs en Allemagne. Elle s'opère à deux niveaux: premièrement, l'immigrant perpétue son ancien mode de vie, malgré

31 Régine Robin (Régine Ajzersztejn, d'origine polonaise), La Québécoite, roman, Montréal, Québec/Amérique, 1983, p. 80.

32 Une des meilleures illustrations de cette problématique reste le texte de Mona Latif Ghattas, d'origine égyptienne, Le double conte de l'exil, Montréal, Boréal, 1990, où Manitakawa-Madeleine, d'origine autochtone, qui travaille dans une buanderie montréalaise, constate le mépris des francophones de souche envers des Asiatiques, derniers sur l'échelon de la hiérarchie sociale. Pour les clichés concernant les immigrants, voir surtout les p. 102 et suiv. 
un environnement l'incitant à transgresser son ancien contexte culturel; deuxièmement, il est frustré de constater que la population d'accueil ne l'invite pas à participer à ses rituels, coutumes, habitudes et qu'elle ne lui accorde qu'une place à l'échelon inférieur, souvent âprement disputée, sur le marché du travail. Au Québec, la situation de l'immigrant italien, par exemple, s'aggrave du fait qu'il accomplit difficilement le deuil de la patrie perdue et que le Québec, perçu comme le nouveau pays-"nation", est luimême incapable d'opter pour une identité (québécoise, canadienne ou américaine, $c f$. note 28). Il n'est donc pas surprenant que, parmi les immigrants, ce soit surtout l'intellectuel italien qui opte pour un Québec autonome, ne considérant plus sa vie au Québec comme une étape passagère, comme d'autres immigrants le font pour des raisons économiques ou politiques ${ }^{33}$. Cependant, plusieurs d'entre eux se rendent compte qu'après plusieurs décennies passées au Québec, il est devenu extrêmement difficile de retourner vivre au pays d'origine: l'immigrant qui n'a pas accompli son travail de deuil de l'ancienne patrie oscillera toujours devant son choix d'appartenance ${ }^{34}$.

Marco Micone représente l'Italie comme la mère trop pauvre qui ne peut nourrir ses enfants et les abandonne à un pays plus "riche" qu'elle, d'où ils vont envoyer une bonne partie de leur salaire afin de soutenir les familles - procédé en tous point identique à celui de plusieurs auteurs turcs (surtout de la deuxième génération) qui décrivent leur attachement à la Turquie (la mère qui les a abandonnés) et leur exil en Allemagne, exil empreint de difficultés d'adaptation et souvent perçu comme une profonde injustice de la vie (Aras Ören, Yüksel Pazarkaya, E. S. Özdamar, Hakk1 Keskin et al.). Les (anti)héros masculins de Micone luttent,

33 Voir Hans-Jürgen Greif, "Écrire en terre d'accueil. La littérature allophone au Québec", Québec français, printemps 1997, p. 65-69, et $i d$., "Französisch schreiben im Gastland", Dokumente, n 4, 1996, p. 293-299.

34 Situation analogue en Allemagne, pour ce qui est des immigrants turcs qui, bien que regroupés souvent dans des enclaves-ghettos (comme à Berlin et Francfort), ne sont plus en mesure d'assumer leur vie en Turquie. Après trente ou quarante années passées en RFA, ils sont déphasés devant l'évolution de leur ancienne patrie. La situation est particulièrement dramatique pour leurs enfants qui se sentent davantage allemands que turcs. Voir Renan Demirkan, "Die Brücke im Januskopf" (Le pont dans la tête à deux visages"), Claus Leggewie/Zafer Senocak, op. cit., p. 79-83, qui réclame la double nationalité pour les ressortissants étrangers afin de leur faciliter la décision "où mourir". 
104

pendant un temps, contre le transfert de comportements typiques du mezzogiomo, pour finalement succomber devant les traditions familiales ${ }^{35}$, comme Johnny-Giovanni qui, dans la pièce de théâtre Addolorata, tente de reprendre en vain avec sa jeune femme, Lolita-Addolorata, le jeu comportemental des parents, nés en Italie. Si cette pièce, très efficace, présente le tiraillement de la jeune génération des Italo-Québécois entre pays d'adoption et pays d'origine (permettant des lectures sociocritiques et psychanalytiques), la série d'essais Le figuier enchanté fait pleinement ressortir la question identitaire: "Ni tout à fait italienne, ni tout à fait québécoise, ma culture est hybride" (p. 100) ${ }^{36}$.

Cette double appartenance semble poser problème aux ItaloQuébécois: au lieu de tenter, comme le suggèrent leurs collègues Oliver et SAID en Allemagne (et dans un contexte culturel somme toute assez clairement défini), une interaction entre les deux cultures, ils restent désemparés devant un pays d'accueil qui hésite devant sa propre identité. Ainsi, Antonio D'Alfonso, dont le cheminement intellectuel se compare à celui de Micone, et qui a délaissé l'usage de l'anglais pour adopter le français, se demande, dans Auril ou l'anti-passion: "Qui suis-je? Je me pose la question. Moi, Québécois, dois-je me dire Italien? Moi, Italien, dois-je me dire Québécois? Les réponses ontologiques ne surgiront nullement du concept de "pays". Un pays, c'est quoi au juste? Un territoire, une nation, ou pire, une mythologie d'enracinement?" (p. 157). Du coup, D'Alfonso lie l'incertitude identitaire à l'espace linguistique ${ }^{37}$. Ce questionnement rejoint précisément celui des

35 Pour une analyse plus en détail de la question identitaire des ItaloQuébécois, voir les études suivantes: Réal Ouellet, "Identité québécoise, permanence et évolution ", Laurier Turgeon, Jocelyn Létourneau, Khadiatoulah Fall (dir.), Les espaces de l'identité, Québec, Les Presses de l'Université Laval, 1997 , p. 62-98 (avec Alain Beaulieu et Mylène Tremblay), et le texte de sa conférence "Nomadisme et enracinement culturel chez les écrivains italoquébécois", Colloque de Carleton, Ottawa, octobre 1990; Simon Harel, "L'exil dans la langue maternelle: l'expérience du bannissement "Québec Studies, op. cit., p. 23-30, et id., Le voleur de parcours: identité et cosmopolitisme dans la littérature québécoise contemporaine, coll. L'univers du discours, Longueil, Le Préambule, 1988, plus particulièrement les $1^{\text {er }}$ et VI ${ }^{\mathrm{e}}$ chapitres, "Cosmopolitisme et altérité " et "L'espace des mots".

36 Marco Micone, Addolorata, Montréal, Éditions Guernica, 1984; id., Le figuier enchanté, Montréal, Boréal, 1992.

37 Antonio D'Alfonso, Avril ou l'anti-passion, roman, Montréal, VLB éditeur, 1990. La même thématique avait déjà été traitée dans L'autre rivage, poésie, 
écrivains d'origine turque de la première génération (Özdamar), arrivés dès le plus jeune âge en Allemagne, avec la différence que les allophones en territoire allemand opposent leur propre tradition à une culture nationale qui se ferme devant eux, enchâssée dans une solide croyance religieuse, sans abandonner l'idée d'un éventuel métissage culturel.

Certains écrivains allophones au Québec tendent non pas vers une remise en question sans cesse renouvelée de leur appartenance culturelle, mais plutôt vers une "globalisation" de leur statut; tout en pratiquant une écriture métisse, avec sa thématique du deuil du pays perdu et le questionnement sur l'Ici et le Maintenant, ils établissent le contact avec le continent nordaméricain.

Plus que tout autre, Naïm Kattan, d'origine irakienne, semble avoir connu dès l'enfance non seulement le frottement des cultures, mais également leur acceptation mutuelle et leur transfert. Dans son roman autobiographique Adieu Babylone, il raconte une scène significative: lors d'une discussion entre élèves du lycée, fréquenté par des musulmans arabes et des juifs, la langue utilisée est d'abord l'arabe, ensuite, les écoliers utilisent, d'un commun accord, le dialecte juif de Bagdad, puisqu'ils s'en servent plus facilement pour exprimer des concepts complexes. Kattan ne cesse de douter de lui-même. Il reprend souvent le récit de son arrivée au Canada, ses difficultés d'insertion dans une nouvelle culture, son étonnement devant le Québec qui, malgré la langue, ne ressemble en rien à la France. Dans La fiancée promise, l'auteur décrit sa formation comme "citoyen du monde"; dans son essai "Le réel et le théâtral", il avait déjà dit: "Je n'accepte pas la fixité des lieux sûrs et le confort des certitudes " ${ }^{38}$, ce qui

Montréal, VLB éditeur, 1987, où il introduit une dimension interculturelle: "Quand j'écris, j'ai en tête la mémoire d'une langue et j'exprime cette mémoire dans une autre langue. Un Mariage de mémoires. (p. 126) Voir également le recueil de poésie d'un autre Italo-Québécois, Fulvio Caccia, Irpinia, Guernica, Montréal, 1983.

38 Naïm Kattan, "Le réel et le théâtral ", Le choix de Naïm Kattan dans l'œuvire de Naïm Kaltan, Charlesbourg, Les presses laurentiennes, 1987, p. 25; id., Adieu, Babylone, roman, Montréal, La Presse, 1975, La fiancée promise, roman, Montréal, Hurtubise HMH, 1993, ou encore le recueil de nouvelles La reprise, Ville LaSalle, HMH, coll. "L'Arbre", 1985, où le thème de la liberté cle l'individu est prépondérant. Il ne s'agit là que de quelques exemples tirés de l'ouvre importante de l'auteur. 
106

résume son existence fragmentée et son appartenance culturelle changeante (juive, irakienne, française, canadienne/québécoise). Contrairement à Régine Robin, par exemple, sa judaïté n'est qu'un accident de parcours; mais elle lui a permis de constater sa différence culturelle dans son pays d'origine. Kattan quitte l'Irak parce qu'il veut vivre librement, dans la culture de son choix, sans s'identifier à l'un ou l'autre groupe ethnique, les embrassant tous et prônant l'amalgame des cultures, sans jamais réprimer celle d'origine.

Sans insister sur le métissage culturel (difficile, selon elle), la romancière d'origine chinoise Ying Chen reprend, dans ses premiers textes, La mémoire de l'eau et Les lettres chinoises, le thème du pays perdu et de l'insertion dans le contexte nord-américain: tous deux décrivent des moments décisifs dans la vie des protagonistes (la révolution chinoise et le problème identitaire entre le temps ancien et le nouveau; le passage d'un jeune Chinois en Occident et l'indécidabilité de son identité affective). Mais déjà, quatre ans à peine après la parution de son premier roman, Chen prend ses distances en ce qui concerne le deuil et ses relations avec le pays natal. Dans une récente entrevue, elle dit: "Mes relations avec la Chine demeurent trop complexes. C'est un peu comme un vieil amour. Il y a beaucoup d'amertume là-dedans. [...] Les lettres chinoises sont un peu mes premières impressions. Je pensais les choses d'une manière un peu superficielle quand je les écrivais. " 39 Son troisième roman, L'ingratitude, se déroule en Chine, mais se place délibérément hors de l'écriture métisse pour développer le thème de l'étrangeté entre membres d'une même famille, plus précisément entre une jeune fille et sa mère. $\mathrm{Ce}$ roman, où la narratrice pose un regard impitoyable sur les relations interpersonnelles, n'obéit donc qu'indirectement à la logique de la thématique des textes allophones: au lieu de placer son texte entre la Chine et le Québec, Chen démontre l'incompréhension et les tensions entre êtres humains. Que le roman se déroule en milieu chinois ne lui confère que de la couleur locale, mais ne le place guère sous l'enseigne de l'exotisme. Ainsi, Chen se distingue clairement d'autres écrivaines allophones, Mona Latif Ghattas, Nadine Ltaif, Bach Mai, pour n'en nommer que quelques-unes, qui pratiquent l'écriture métisse en plaçant leurs

39 Christian Hommel: "Ying Chen ou l'exil des mots", Québec-France, printemps 1997, p. 28. 
protagonistes entre pays d'origine et pays d'accueil et en accentuant leur inconfort vis-à-vis de l'identité indécidable ${ }^{40}$.

\section{Après les mythes, une nouvelle voie}

Nous avons dit que le Québec, dont les assises culturelles sont très différentes de celles d'une nation européenne, s'est composé une identité multiple et fractionnée. Les contacts des premiers colons français avec la population autochtone coincidaient avec leur désir de retrouver, dans ce Nouveau Monde, le paradis perdu, et de fonder un pays "nouveau" (souvent les noms de territoires ou de villes européennes portent, en Amérique du Nord, l'épithète "nouveau": Nouvelle France, Nouvelle Orléans, Nouveau-Brunswick, Terre Neuve, Nouvelle Angleterre, Nouvelle Écosse etc.). Dans son analyse du mythe américain dans la littérature nord-américaine, Jean Morency ${ }^{41}$ soutient que, lors du passage de l'Ancien vers le Nouveau Monde, l'Indien devient le médiateur dans le processus de l'américanisation. Comme l'immigrant ne peut oublier son héritage européen, et rêvant d'imiter le mode de vie de l'Indien (marqué par le monde sauvage, illimité, empreint de liberté), il hésite éternellement entre les pôles d'attraction. Morency décrit bien le dilemme du Québécois qui "n'accepte pas l'Indien, mais sans vouloir se l'avouer il rêve d'en devenir un, sans renier pour autant sa nature de Blanc, ou l'idée qu'il se fait de sa culture et sa civilisation: il va donc à la chasse ou la pêche, ou bien il fait du camping sauvage, mais de façon purement épisodique. Il veut s'accaparer l'âme de l'Indien mais sans pour autant changer de peau".

40 Pour Latif Ghattas, voir note 32. De Nadine Ltaif, également d'origine égyptienne, lire son recueil de poésies Entre les fleuves, Montréal, Guernica, 1991 (cette maison, dirigée par Antonio D'Alfonso, édite beaucoup d'écrivains allophones, plus particulièrement italophones). Sur Ltaif, voir l'étude de Christl Verduyn, "Nouvelles Voies/voix: l'écriture de Nadine Ltaif", Québec Studies, op. cit., p. 41-48. Dans ce même numéro, consulter un important article de Jack E. Yeager, "Bach Mai's francophone eurasian voice: remapping margin and center", p. 49-64, sur le "roman reportage" de Mai, D'ivoire et d'opium, Sherbrooke, Éditions Naaman, 1985, où l'auteure pose la question "Que veut dire être québécois?"

41 Jean Morency, Le mytbe américain dans les fictions d'Amérique. De Washington Irving à Jacques Poulin, Québec, Nuit blanche Éditeur, 1994, p. 147. Morency a recours aux travaux de Mircea Eliade, notamment La nostalgie des origines, Paris, Gallimard, 1978. 
108

L'immigrant constate que le Québécois se sent encore, d'une part, abandonné par la mère-patrie et colonisé par l'autre parent (de moins en moins, comme le soutient Heinz Weinmann, cf. note 28); d'autre part, il s'identifie à l'Indien qui a perdu la bataille contre les colons blancs - comme il se sent perdant devant le nombre écrasant d'Anglophones qui l'entourent - et qui a su garder sa dignité en se retranchant dans son mode de vie (son identité) empreint le liberté et de communion avec la nature. L'immigrant d'aujourd'hui peut comprendre le sentiment d'abandon et la volonté de s'affirmer dans un pays autonome. Mais il ne peut avoir accès au mythe de l'Indien, du coureur de bois, à la nostalgie des premiers temps, ravivée sans cesse dans l'imaginaire québécois ${ }^{42}$. Un texte comme Volkswagen Blues de Jacques Poulin, sans doute un des meilleurs exemples de la réflexion québécoise sur l'identitaire, exclut et englobe à la fois l'immigrant moderne:

L'Amérique! Chaque fois qu'il entendait prononcer ce mot, Jack sentait bouger quelque chose au milieu des brumes qui obscurcissaient son cerveau. [...] C'était une idée enveloppée de souvenirs très anciens - une idée qu'il appelait le "Grand rêve de l'Amérique". Il pensait que, dans l'histoire de l'humanité, la découverte de l'Amérique avait été la réalisation d'un vieux rêve. [...] Il prétendait que, depuis le commencement du monde, les gens étaient malheureux parce qu'ils n'arrivaient pas à retrouver le paradis terrestre. Ils avaient gardé dans leur tête l'image d'un pays idéal et ils le cherchaient partout. Et lorsqu'ils avaient trouvé l'Amérique, pour eux c'était le vieux rêve qui se réalisait et ils allaient être libres et heureux. Ils allaient éviter les erreurs du passé. Ils allaient tout recommencer à neuf. ${ }^{43}$

L'immigrant d'aujourd'hui connaît bien le rêve du recommencement et du renouveau. La crainte de perdre son identité en

42 Au sujet de la question identitaire des francophones au Canada, voir Lucie Hotte (dir.), La problématique de l'identité dans les littératures francophones du Canada et d'ailleurs, Le Nordir, Hearst, 1994, tout particulièrement François Ouellet, "Portrait du héros "en jeune saint-je". La rage et Cowboy de Louis Hamelin", p. 121-128; Gilles Thérien, "L'Indien imaginaire: une hypothèse", Rechercbes amérindiennes au Québec, vol XVII, no 3, automne 1987 , p. 3-21. Parmi les romans traitant des rapports entre Blancs et Indiens, citons Louis Hamelin, Cowboy, Montréal, XYZ éditeur, 1992, et Robert Lalonde, Le dernier ëté des Indiens, Paris, Seuil, 1982.

43 Jacques Poulin, Volkswagen Blues, Montréal, Québec/Amérique, 1984, p. 100-101. 
s'éloignant du sol natal qui confère langue et identité ( $c f$. la figure de Théo Waterman, frère du protagoniste de Volkswagen Blues, retrouvé à San Francisco après une longue traversée du continent, et qui a perdu sa langue maternelle) ne le touche pas (encore). Toutefois, Poulin indique une nouvelle voie capable d'inclure la "vieille" et la "nouvelle souche", tout comme le font les jeunes auteurs allophones et certains écrivains appartenant à la littérature nationale en Allemagne ${ }^{44}$ : Jack Waterman entreprend le voyage en compagnie d'une métisse qui se plaint qu'elle n'appartient ni au monde des Blancs ni à celui des Indiens. Jack lui répond: "Vous dites que vous êtes "quelque chose entre les deux". [...] Eh bien, je ne suis pas du tout de votre avis. Je trouve que vous êtes quelque chose de neuf, quelque chose qui commence." (p. 224)

Il est significatif qu'un an avant la publication de Volkswagen Blues une voix parmi les écrivains allophones ait posé la question de l'identitaire chez l'immigrant. Si Poulin parle de sa quête d'une identité québécoise/nord-américaine, Régine Robin, dans son roman La Québécoite, traite éloquemment de la voie de l'avenir, englobant "vieilles" et "nouvelles" souches dans un programme qui pourrait être valable pour toute société ayant des rapports de bordure entre cultures ${ }^{45}$. Le roman, une projection de différentes possibilités d'une même existence, et entièrement écrit au conditionnel, est une mise en pratique des travaux théoriques de Robin, du concept de la postmodernité à celui de l'interlangue en passant par le problème de l'américanité. Reconnaissant qu'un immigrant ne peut s'approprier l'imaginaire de celui appartenant à la "vieille souche", elle se pose la question du rôle que peut jouer l'étranger au Québec, et plus particulièrement à Montréal ${ }^{46}$.

44 Les propos de Cirak, Senocak, Oliver sont repris par certains auteurs allemands, comme Eva Demski, qui développe dans son roman Afra, Frankfurt s. le Main, Frankfurter Verlagsanstalt, 1995, le destin d'une Noire dans l'Allemagne de l'après-guerre.

45 Régine Robin, La Québécoite, Québec/Amérique, Montréal, 1993. Cf. Anthony Purdy, "La Québécoite de Régine Robin: une approche dialogique", Louise Milot et Jaap Lintfelt (dir.) Le roman québécois depuis 1960, Presses de l'Université Laval, Sainte-Foy, 1992, p. 88-104. Soulignons que les romans de Poulin et de Robin ont été publiés par la même maison cl'édition.

46 Voir Régine Robin, Le cheval blanc de Lénine ou l'bistoire autre, Bruxelles, Éditions complexes, 1979 ; id, Le roman mémoriel. De l'bistoire à l'écriture du bors-lieu, op. cit. (note 18); id., Le deuil de lorigine. Une langue en trop, la langue en moins, Saint-Denis, Presses universitaires de Vincennes, 
Avant tout, elle constate que "[l]a parole immigrante est insituable, intenable. [...] Elle ne s'installe pas. Parole sans territoire et sans attache, elle a perdu ses couleurs et ses tonalités" (p. 198), s'opposant à la mémoire collective de la majorité francophone (p. 129-130).

Puisque la société québécoise est - et sera — de plus en plus fractionnée, des changements profonds s'opèreront en son sein : le Québec se dirige vers une méta-société, plurielle, qui n'a plus rien de commun avec celle du passê, et qui avait été incapable de se détacher du deuil de la patrie perdue ou qui l'a trahie. Cette ancienne société pouvait encore survivre à l'ère du multiculturalisme des années soixante-dix, permettant aux différents groupes ethniques de rester largement imperméables. Comme le Canada (et le Québec) n'ont pas suivi l'exemple américain du melting pot, obligeant les immigrants à abandonner leur identité d'origine, Robin suit le principe de la transculture, générant un nouveau cosmopolitisme, basé sur le jeu intertextuel des cultures, s'insérant ainsi parfaitement dans le concept de la postmodernité. La voie s'ouvre à de nouvelles "musiques de la langue", pratiquées par tous les écrivains allophones, de Dany Laferrière à Sergio Kokis, qui délaissent de plus en plus la littérature migrante pour l'écriture métisse, habitée encore par la mémoire originelle, mais s'appropriant l'Ici et le Maintenant ${ }^{47}$. Le programme d'une société plurielle se profile dans le roman de Robin: "Le Québec tout doucement s'en irait vers une société plurielle sans qu'il n'y paraisse. Témoins de cette métamorphose inconsciente, ils [la narratrice et son ami, originaire du Paraguay] en seraient aussi les obscurs et anonymes artisans" (p. 195)

\section{Vers la transculturation}

Dès lors il devient clair que les préoccupations des auteurs allophones se recoupent, en Allemagne comme au Québec,

coll. "L'imaginaire du texte", 1993, où elle prend comme exemples Freud, Canetti, Kafka et Perec, tous marqués, à des degrés divers, par la langue perdue. Elle reprend ses réflexions dans son essai Kafka, Paris, Belfond, 1989, et son recueil de nouvelles L'immense fatigue des pierres, Biofictions, Montréal, XYZ éditeur, coll. "Étoiles variables", 1996. Quant au concept de l'interlangue, voir Robin, Le roman mémoriel, p. 171. Pour celui de la postmodernité, voir ibid., p. 189.

47 Pour la répartition des immigrants au Québec, voir note 29. 
puisqu'ils suivent l'enseignement du Cubain Fernando Ortiz, postulant la transculture, et délaissant les concepts de l'acculturation, du multiculturalisme ou encore de l'assimilation ${ }^{48}$. Le texte de Zehra Curak portant sur l'intégration des différentes cultures dans son propre mode de vie tend non seulement vers la multiplication des identités comme le postule Régine Robin, mais il exprime, de la même manière, le désir de transgresser les frontières culturelles ${ }^{49}$, de délaisser l'ethnicité et d'écrire un nouveau roman mémoriel, c'est-à-dire "les diverses formes d'appropriation collective du passé, depuis la mémoire officielle jusqu'à la mémoire fonctionnalisante de la littérature, depuis la mémoire savante, élaborée par les historiens jusqu'aux mémoires de groupes minoritaires et générationnels " 50 .

Les écrivains allophones se détournent ainsi du consensus entre groupes ethniques, défendu par l'État, comme de la volonté de ces mêmes groupes qui désirent préserver une société disparate et fractionnée. Ils visent une nouvelle dynamique entre groupes de vieille et de nouvelle souches, créant ainsi une identité basée sur la transculturation et un jeu de proximité-distance très souple à l'intérieur du tissu urbain: "Aux lieux de l'entre-soi, répondent en contrepoint ces lieux de l'entre-tous "51. Dépassant la politique d'intégration de l'État, bon nombre d'écrivains allophones, en Allemagne comme au Québec, peuvent percevoir dans l'histoire du calife et de son vizir le désir de voler avec les ailes de l'autre. Mais ce changement de l'identité n'était pas dicté

48 Comme les romans de Dany Laferrière, d'origine haittienne, de Comment faire l'amour avec un Nègre sans se fatiguer, Montréal, VLB éditeur, 1985, à Le goût des jeunes filles, Montréal, VLB éditeur, 1992 et ceux de Sergio Kokis, Le pavillon des miroirs (1994), Negão et Doralice (1995) et Errances (1996), tous publiés à Montréal chez XYZ éditeur. Pour l'esthétique de Kokis, voir H.-J. Greif, "Sergio Kokis et les langages de la création", Nuit Blanche, $\mathrm{n}^{\circ} 66$, printemps 1997, p. 46-47. Consulter également Pierre Laurette, Hans-George Ruprecht (dir.), Poétiques et imaginaires. Francopolypbonie littéraire des Amériques, Paris, L'Harmattan, 1995, plus particulièrement la partie VII.

49 Les articles de Jean Lamore, "Transculturation: naissance d'un mot", Méramorpboses d'une utopie, op. cit., p. 43-47, et, ibid., Alain Médam, "Ethnicité et cité, entre le "co" et le "dis", le "trans"?", p. 49-61, rejoignent les réflexions de Nancy Houston dans Désirs et réalités. Textes choisis 19781994, Montréal, Leméac, 1995, plus particulièrement dans la $3^{e}$ partie, "Exil, langue, identité".

50 Régine Robin, "Sortir de l'ethnicité", Métamorphoses d'ıne utopie, op. cit. p. 26.

51 Alain Médam, op. cit., p. 59. 
112

par la nécessité - il était né d'une fantaisie, aboutissant à une aventure cocasse. Pour l'immigrant d'aujourd'hui, il ne s'agit plus de changer d'identité, de perdre sa langue et d'être l'étranger de l'autre, mais de prendre son envol avec des ailes de l'autre. Ce que dit Zehra Cirak en s'adressant à son partenaire allemand traduit le message de l'immigrant au Québec:

Tu es droitier je suis gauchère/ comme de raison nous rêvons de voler/ tu as une aile sur ton épaule gauche/et moi, bien sût, sur ma droite/ en battant les ailes ensemble nous désirons/ nous envoler/ avec nos épaules soudées l'une à l'autre

Ici, sur la terre ferme/ nous sommes d'accord depuis longtemps déjà/ mais gare à nous dans les airs là-haut nous pourrions/ nous déchirer/ alors nous nous tenons fermement par la main/ ma gauche dans ta droite/ et nous nous frottons chaque soir/ mutuellement nos omoplates qui nous démangent ${ }^{52}$

52 Zehra Crrak, "Fremde Flügel auf eigener Schulter" ("Des ailes êtrangères sur mon épaule"), Fremde Flügel auf eigener Schulter, Poèmes, Kiepenheuer und Witsch, 1994, p. 98. 